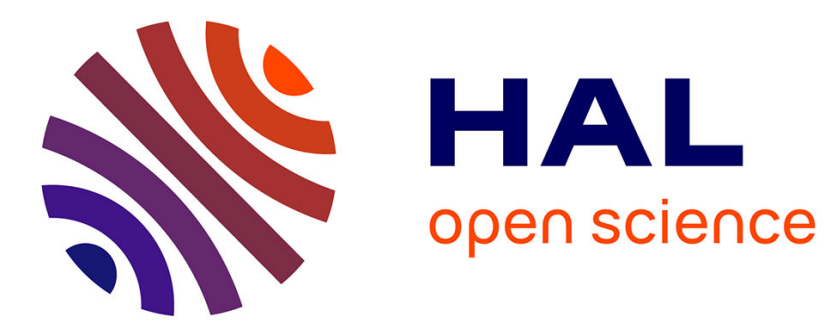

\title{
In vitro mouse model in Duchenne muscular dystrophy diagnosis using 50-MHz ultrasound waves
}

\author{
D. Laux, H. Blasco, J.-Y. Ferrandis, Gerald Hugon, Gilles Despaux, A.
}

Leydier, Dominique Mornet

\section{> To cite this version:}

D. Laux, H. Blasco, J.-Y. Ferrandis, Gerald Hugon, Gilles Despaux, et al.. In vitro mouse model in Duchenne muscular dystrophy diagnosis using $50-\mathrm{MHz}$ ultrasound waves. Ultrasonics, 2010, 50 (8), pp.741 - 743. 10.1016/j.ultras.2010.04.003 . hal-01616073

\section{HAL Id: hal-01616073 \\ https://hal.science/hal-01616073}

Submitted on 19 Apr 2020

HAL is a multi-disciplinary open access archive for the deposit and dissemination of scientific research documents, whether they are published or not. The documents may come from teaching and research institutions in France or abroad, or from public or private research centers.
L'archive ouverte pluridisciplinaire HAL, est destinée au dépôt et à la diffusion de documents scientifiques de niveau recherche, publiés ou non, émanant des établissements d'enseignement et de recherche français ou étrangers, des laboratoires publics ou privés. 


\title{
In vitro mouse model in Duchenne muscular dystrophy diagnosis using $50-\mathrm{MHz}$ ultrasound waves
}

\author{
D. Laux ${ }^{\mathrm{a}, *}$, H. Blasco $^{\text {a }}$, J.Y. Ferrandis ${ }^{\mathrm{a}}$, G. Hugon ${ }^{\mathrm{b}}$, G. Despaux $^{\mathrm{a}}$, A. Leydier ${ }^{\mathrm{a}}$, D. Mornet $^{\mathrm{b}}$ \\ a University Montpellier II, Institut d'Electronique du Sud IES UMR CNRS 5214, CC082, Bât 13, Place Eugène Bataillon, 34095 Montpellier, France \\ ${ }^{\mathrm{b}}$ University Montpellier I, INSERM, ERI 25, Unité "Muscle et pathologies", EA 4202, CHU Arnaud de Villeneuve, 371 Avenue du Doyen G. Giraud, \\ Bâtiment INSERM Crastes de Paulet, 34295 Montpellier Cedex 5, France
}

\section{A R T I C L E I N F O}

Keywords:

Ultrasonic attenuation

DMD

Mdx and BL10 mice

\begin{abstract}
A B S T R A C T
Duchenne muscular dystrophy (DMD) is caused by the absence of dystrophin, the protein that plays a key mechanical role in maintaining muscle membrane integrity. One of the major consequences of dystrophin deficiency is the degeneration of muscle fibres, with a progressive loss in muscle strength. The objective of this research was to find an ultrasonic parameter sensitive to DMD, which could give relevant information related to microstructure if compared to traditional investigations such as morphometrical analysis. This "in vitro" study focused on the Mdx mouse model and investigated the potential differences between wild-type and dystrophin-deficient mice diaphragms. Using a $50 \mathrm{MHz}$ ultrasonic sensor built in our group, we recorded an increase in ultrasonic wave attenuation in the dystrophin-deficient samples in comparison with normal muscles. A correlation between attenuation, mouse age and the percentage of non-muscular proportion in muscle was observed. As Mdx mouse is the best animal model for DMD and reproduces the degenerative pattern observed in human DMD muscles, this approach could be a powerful tool for in vitro DMD investigation and, more generally, for the characterisation of muscle properties.
\end{abstract}

\section{Introduction}

In many mechanical diseases, muscle wasting and weakness are associated with abnormalities in the structure or expression of the components of myofibre [1]. For example, dystrophin deficiency [2] has been shown to result in myopathic phenotypes in human (i.e. dystrophinopathy) and animal [3] skeletal muscle. The muscle weakness is correlated with an increase in interstitial connective tissue, leading to fibrosis and progressive adiposis in the myofibres.

Most of pre clinic physiopathologic and therapeutic studies concerning Duchenne muscular dystrophy (DMD) have been and are today performed on Mdx mice [4-6].

For Mdx mouse, all skeletal muscles are affected by necrosis. This degeneration begins 15 days after birth but only the diaphragm muscle has an evolution which is comparable to the evolution observed in human DMD. It exhibits a high dystrophic pattern and reproduces the degenerative pattern observed in human DMD muscles [7]: no muscle regeneration, fibrosis, adipose... Even if symptoms observed in mice are attenuated compared to human DMD, the animal constitutes an excellent model for molec-

\footnotetext{
* Corresponding author. Tel.: +33 467143430 .

E-mail addresses: laux@lain.univ-montp2.fr, didier.laux@ies.univ-montp2.fr (D. Laux).
}

ular interactions and their consequences on membrane cells. Hence, Mdx diaphragm muscle constitutes an excellent model for pre-clinical physiopathologic and therapeutic studies and has been chosen for the present study.

In this work, we propose an ultrasonic technique to detect defects in Mdx diaphragms. It could give new information compared to traditional investigations such as morphometrical analysis.

The ultrasonic parameter chosen was the longitudinal ultrasonic attenuation, which is sensitive to heterogeneity and fat content $[8,9]$. As one of the major effects of DMD is the progressive invasion of muscle by adipose and fibrotic tissue, the attenuation parameter could be relevant. If a correlation is established between attenuation and non-muscular area, the parameter attenuation could be used on mice diaphragms to evaluate the non-muscular area. As the non-muscular area is an indicator of DMD evolution one could follow the DMD evolution with attenuation.

The diaphragms from 3-, 10-, 12- and 18-month-old BL10 (normal animal) and Mdx mice were studied with an ultrasonic method especially adapted to mice diaphragms. Then, using standard biological techniques (histochemistry and morphometrical analysis), the percentage of non-muscular proportion was deduced. The attempt to correlate these two parameters will be discussed at the end of the experiments. 


\section{Experimental approach}

\subsection{Mice samples}

Control (C57 BL/10) and Mdx mice were purchased from Jackson Laboratory (Bar Harbor, ME, USA) and selected according to age ( $3,10,12$ and 18 months). The study was approved by our university's Institutional Animal Care Use Committee (agreement No. A 34-545). Following a standard protocol, the diaphragm muscles were dissected immediately after death and divided into two parts. Each diaphragm was cut into two strips (left and right). The dimensions of each strip were about $2 \mathrm{~cm}$ (length) $\times 4 \mathrm{~mm}$ (width) $\times 400 \mu \mathrm{m}$ (thickness).

\subsection{Ultrasonic measurements}

Ultrasonic velocity and attenuation measurements are not always easy in soft tissues because the precise measurement of sample thickness is quite difficult. We thus decided to use a modified approach usually dedicated to experiments on fluids. We have already used this method for characterising liquid sugar [10].

A 50-MHz piezoelectric transducer was built in our group to study these small and thin mouse diaphragms. This frequency was chosen to avoid overlapping between multiple reflections in the samples. The sensor is made of a thin piezoelectric crystal (thickness: $45 \mu \mathrm{m}$ ) settled on a silica rod and is excited with an electrical pulse generator. Thanks to the inverse piezoelectric effect, this electric excitation is converted into an ultrasonic (mechanical) wave that propagates through the silica rod to reach the sample. The silica rod, sometimes called the delay line, ensures the emission of the ultrasonic wave in the far field region where the ultrasonic pressure is quite spatially homogeneous. It also constitutes a wave-guide for the ultrasonic waves. For our sensor the delay line length is $20 \mathrm{~mm}$. A photograph of the sensor is presented in Fig. 1. One can notice that the delay line diameter is small: $3 \mathrm{~mm}$. We chose this diameter because the diaphragms are also small sample (see Section 2.1) with comparable dimensions.

Typically, an ultrasonic measurement is performed as follows: just after dissection, the sample is settled on a hard material ( $2 \mathrm{~cm}$ glass plate), which constitutes an ultrasonic reflector. The ultrasonic sensor is then approached. When contact with the sensor tip occurs, an ultrasonic wave propagates through the sample, is reflected from the reflector, propagates again in the sample, is converted into an electric signal by the piezoelectric, and the echo is then visualised on an oscilloscope. Then, using a micrometric stepper motor, the sensor tip is slowly approached, leading to a

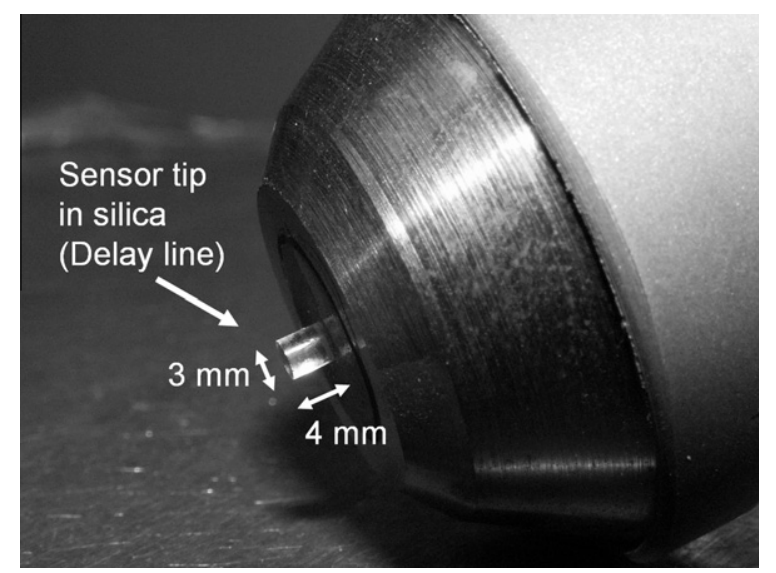

Fig. 1. Ultrasonic sensor for attenuation measurements. progressive reduction in the sample thickness. Such an experiment can be called an indentation procedure.

The thinner the sample becomes, the higher the ultrasonic signal amplitude becomes. If " $z$ " is the vertical axis and $A(z)$ is the amplitude of the ultrasonic echo, one can plot the curve: 20 Lo$\mathrm{g}_{10}(A(z))$ versus $z$. From this curve, the ultrasonic attenuation $\alpha$ can be extracted thanks to a linear fit. If $\eta$ is the slope, the ultrasonic attenuation in decibels per meter is then defined as: $\alpha\left(\mathrm{dB} \mathrm{m}^{-1}\right)=-\eta / 2$.

Concerning the apparatus, we used a pulse generator (model 5900 PR, Olympus, France). With this generator, the sensor is excited by an electrical voltage of $220 \mathrm{~V}$ during $2 \mathrm{~ns}$. The oscilloscope was a WaveRunner, LeCroy Corporation, France. For the stepper motor we chose a Newport (RI, USA.) with a displacement resolution of $1 \mu \mathrm{m}$. All the experiments were remote controlled by personal computer (Dell) via a GPIB IEEE interface (Newport, RI, USA). Data acquisition and signal processing were ensured by software written with Labview 8.1 (National Instruments, France).

Immediately after measurement, the samples were conditioned for histochemical and morphometrical analysis, as described in the following section.

Remark: Ultrasonic measurements were very rapid; less than $3 \mathrm{~min}$. So, diaphragm samples remained at room temperature a very small time and did not dry. Thanks to morphometrical analysis performed before and after ultrasonic tests, we have checked that it was non destructive and that muscle structure was not destroyed during experiment.

\subsection{Histochemistry and morphometrical analysis}

Diaphragm muscles from wild-type and dystrophin-deficient mice were frozen in liquid nitrogen-cooled isopentane, and cryosections were submitted to either haematoxylin or specific primary antibody labelling. The slides were then analysed on a Nikon microscope-based imaging system using Histolab imaging software (Microvision Instruments, France). The $10-\mu \mathrm{m}$ transversally cryostat sections of Mdx and normal diaphragms were stained by haematoxylin and eosin (H\&E) to distinguish between healthy myofibres, showing peripheral nuclei and regenerating myofibres, and degenerating fibres, often present in areas where small regenerating fibres and cell infiltrates were also visible [11-13]. Morphometrical analysis was performed on about 10 cross-sections from diaphragm to obtain more than 1500 fibres analysed. The percentage of total non-muscle area (fibrotic or adipose tissue) was recorded.

\section{Results}

Fifteen mice were studied for each age. Six ultrasonic measurements were performed for each diaphragm, for a total of about 400 measurements. Furthermore, a first batch of mice ( 3 and 10 months) had been studied in 2006, and a second batch (with the same ages) had been studied in 2007; the attenuation results were the same in all cases. Thus, the results presented here are totally reproducible and representative. The acoustic attenuation values of the diaphragm types were between 9 and $32 \mathrm{~dB} \mathrm{~mm}^{-1}$. The results are given in Fig. 2 with their standard deviation. This latter ranged from 1 to $3 \mathrm{~dB} \mathrm{~mm}^{-1}$, depending on the sample.

Remark: Diffraction effects due to the finite size of the piezoelectric element have been quantified with the method proposed in [14]. We found $0.140 \mathrm{~dB} \mathrm{~mm}^{-1}$. This is totally negligible compared to attenuations measured on diaphragms.

As shown in Fig. 2, attenuation increased with mouse age and pathology. Furthermore the ultrasonic attenuation differentiated the two populations of mice, i.e. Mdx and BL10. Even though 


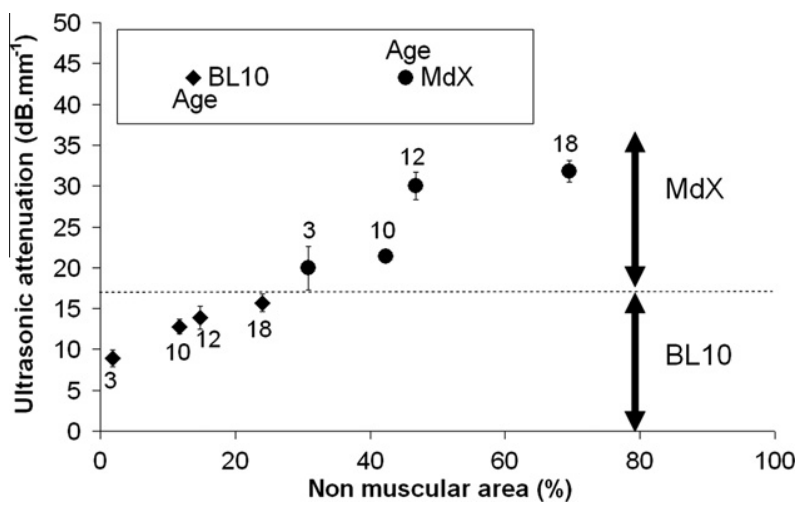

Fig. 2. Ultrasonic attenuation versus percentage of non-muscular area and mice age.

attenuation increased with age, none of the older BL10 mice presented attenuation equal to that measured in the Mdx mice. All the Mdx mice had higher attenuation. Furthermore, a link was observed between ultrasonic attenuation and the non-muscular area. As the pathology progressed, fibrosis and adipose tissue continued to replace muscular cells and ultrasonic attenuation increased. As a fibrotic pattern creates geometrical disorder and generates more ultrasonic diffusion in muscle, it contributes with fat to the increase in attenuation. Separating the two effects (fibrosis and adiposis) is difficult and presents no real interest for our investigations.

\section{Conclusion}

The results presented here demonstrated that ultrasonic longitudinal wave attenuation can give relevant information for in vitro DMD investigation on Mdx mice. This technique could become a new parameter for systematic measurement in mice after dissection and before histochemistry and morphometrical tests.

As Mdx mouse is the best animal model for DMD, some extrapolations of results are possible. It could be performed in the case of therapeutic treatment testing, for example. If a treatment has an effect on ultrasonic attenuation measured on Mdx mouse, an effect on human could be expected.

Furthermore, this study is very promising regarding the results recently obtained in vitro by Tanveer et al. [15] on skin biopsy. These authors demonstrated that the structure of human skin is greatly affected by DMD. As we have demonstrated that the acous- tical approach presented in this paper is valid for DMD investigation, future work could be dedicated to the analysis of skin. This approach could initially be tested in vitro on biopsy specimens because of the small zone analysed by the sensor $(3 \mathrm{~mm} \times 3 \mathrm{~mm})$. A next and last step would be direct in vivo measurement on skin. The appropriate sensors and methods are under currently development in our laboratories.

\section{References}

[1] G.S. Lynch, J.D. Schertzer, J.G. Ryall, Therapeutic approaches for muscle wasting disorders, Pharmacol. Therap. 113 (2007) 461-487.

[2] M. Koenig, A.P. Monaco, L.M. Kunkel, The complete sequence of dystrophin predicts a rod-shaped cytoskeletal protein, Cell 53 (1998) 219-228.

[3] P. Sicinski, Y. Geng, A.S. Ryder-Cook, E.A. Barnard, M.G. Darlison, P.J. Barnard, The molecular basis of muscular dystrophy in the Mdx mouse: a point mutation, Science 244 (1989) 1578-1580.

[4] J.A. Faulkner, R. Ng, C.S. Davis, S. Li, J.S. Chamberlain, Diaphragm muscle strip preparation for evaluation of gene therapies in Mdx mice, Clin. Exp. Pharmacol. Physiol. 35 (7) (2008) 725-729.

[5] M.D. Grounds, H.G. Radley, G.S. Lynch, K. Nagaraju, A. De Luca, Towards developing standard operating procedures for pre-clinical testing in the Mdx mouse model of Duchenne muscular dystrophy, Neurobiol. Dis. 31 (1) (2008) 1-19.

[6] V. Straub, J.A. Rafael, J.S. Chamberlain, K.P. Campbell, Animal models for muscular dystrophy show different patterns of sarcolemmal disruption, J. Cell Biol. 139 (2) (1997) 375-385.

[7] J.D. Porter, A.P. Merriam, P. Leahy, B. Gong J. Feuerman, G. Cheng S. Khanna, Temporal gene expression profiling of dystrophin-deficient (Mdx) mouse diaphragm identifies conserved and muscle group-specific mechanisms in the pathogenesis of muscular dystrophy, Hum. Mol. Genet. 13 (2004) 257-269.

[8] T. Lin, J. Ophir, G. Potter, Correlation of ultrasonic attenuation with pathologic fat and fibrosis in liver disease, Ultrasound Med. Biol. 14 (1988) 729-734.

[9] K.M.U. Tervola, M.A. Gummer, J.W. Erdman, W.D. O'Brien, Ultrasonic attenuation and velocity in rat liver as a function of fat content concentration: a study at $100 \mathrm{MHz}$ using a scanning laser acoustic microscope, J. Acoust. Soc. Am. 77 (1985) 307-313.

[10] D. Laux, G. Levêque, V. Cereser Camara, Ultrasonic properties of water/sorbitol solutions, Ultrasonics 49 (2009) 159-161.

[11] A. Briguet, I. Courdier-Fruh, M. Foster, T. Meier, J.P. Magyar, Histological parameters for the quantitative assessment of muscular dystrophy in the Mdxmouse, Neuromuscular Disord. 14 (2004) 675-682.

[12] K. Hnia, S. Tuffery-Giraud, M. Vermaelen, G. Hugon, D. Chazalette, A. Masmoudi, F. Rivier, D. Mornet, Pathological pattern of Mdx mice diaphragm correlates with gradual expression of the short utrophin isoform Up71, Biochim. Biophys. Acta 1762 (2006) 362-372.

[13] K. Hnia, G. Hugon, F. Rivier, A. Masmoudi, J. Mercier, D. Mornet, Modulation of p38 mitogen-activated protein kinase cascade and metalloproteinase activity in diaphragm muscle in response to free radical scavenger administration in dystrophin-deficient Mdx mice, Am. J. Pathol. 170 (2007) 633-643.

[14] G. Lévêque, E. Rosenkrantz, D. Laux, Correction of diffraction effects in sound velocity and absorption measurements, Meas. Sci. Technol. 18 (2007) 34583462.

[15] N. Tanveer, MC. Sharma, C. Sarkar, S. Gulati, V. Kalra, S. Singh, R. Bhatia, Diagnostic utility of skin biopsy in dystrophinopathies, Clin. Neurol. Neurosurg. 111 (2009) 496-502. 